Finding Yourself at Work: Examining the Influence of Attachment Styles on Organizational Identification

\author{
By \\ Spencer Hewitt \\ HBSc, University of Toronto, 2017 \\ A thesis \\ presented to Ryerson University \\ in partial fulfillment of the \\ requirements for the degree of \\ Master of Science in Management (MScM) \\ in the program of \\ Master of Science in Management \\ Toronto, Ontario, Canada, 2019 \\ (C) Spencer Hewitt, 2019
}




\section{Author's Declaration}

I hereby declare that I am the sole author of this thesis. This is a true copy of the thesis, including any required final revisions, as accepted by my examiners.

I authorize Ryerson University to lend this thesis to other institutions or individuals for the purpose of scholarly research.

I further authorize Ryerson University to reproduce this thesis by photocopying or by other means, in total or in part, at the request of other institutions or individuals for the purpose of scholarly research.

I understand that my thesis may be made electronically available to the public. 


\title{
Abstract \\ Finding Yourself at Work: Examining the Influence of Attachment Styles on Organizational Identification
}

\author{
Spencer Hewitt, 2019 \\ Master of Science in Management (MscM) \\ Ryerson University
}

Understanding why and how employees engage with their organization is integral to the maintenance of a productive workforce. While research on attachment theory in organizations has focused on interpersonal work relationships, recent theory suggests that employees may attach to the organization itself. This study examines whether attachment style influences if and how employees choose to identify with their organization. Specifically, I focus on how adult attachment style influences an expanded form of organizational identification and whether or not person-organization fit and need for organizational identification moderate the hypothesized attachment-identity relationships. The results of a time-lagged study of 362 working adults suggest that attachment anxiety encourages self-definition in terms of the organization while individuals high in avoidance seek to maintain emotional distance from the organization in their identities. No support was found for the hypothesized moderators. The results are framed around potential development of the expanded model of organizational identification. 


\section{Acknowledgements}

I would like to thank my supervisor, Dr. Kristyn Scott, for her continued guidance throughout both this project and the beginning of my academic career. Her expert advice and encouragement has been central in the development of my knowledge and work.

I am also grateful to Dr. Robin Church and Dr. Michael Halinski for their participation on my examination committee as their feedback has helped this paper develop into its final form as it exists today.

Finally I would like to acknowledge the other great professors at Ryerson University that I have had the pleasure of meeting and working with, be it through classes, presentations or otherwise fortunate encounters. The supportive atmosphere encouraged by all faculty have made this a truly positive experience. 


\section{Table of Contents}

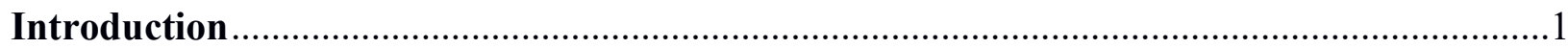

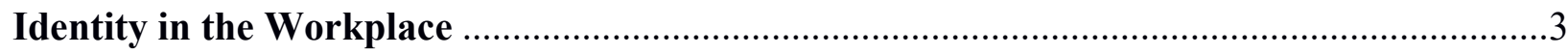

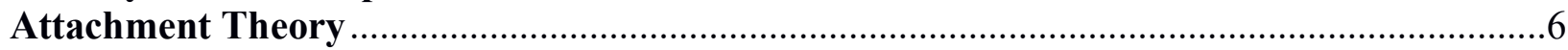

Moderators of Attachment and Organizational Identification .......................................15

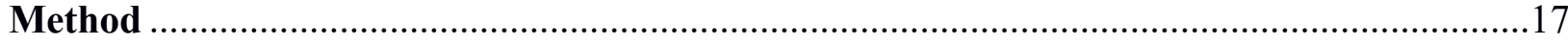

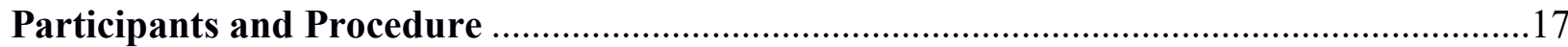

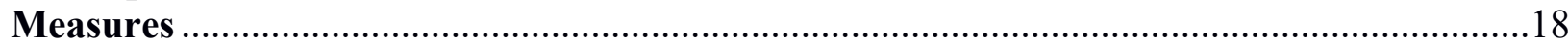

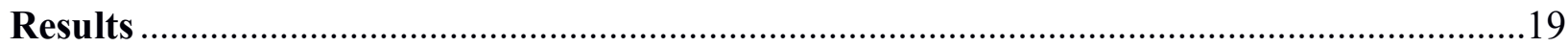

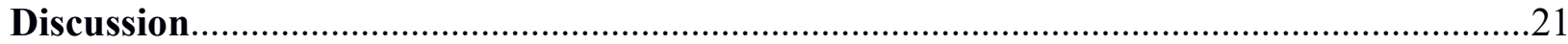

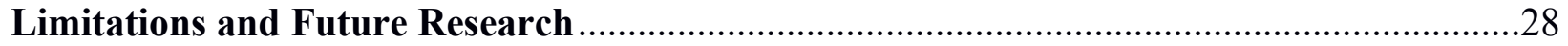

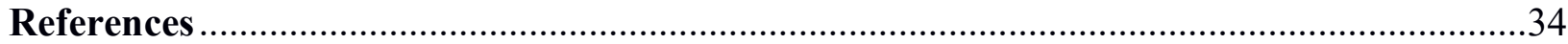




\section{List of Tables}

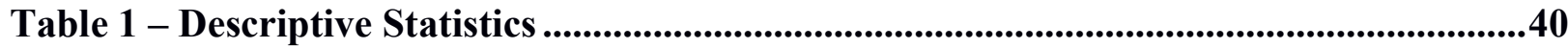

Table 2 - Attachment-Identification Correlations.....................................................................42

Table 3 - Need for Organizational Identification Moderation ..............................................43

Table 4 - Person-Organization Fit Moderation ................................................................44

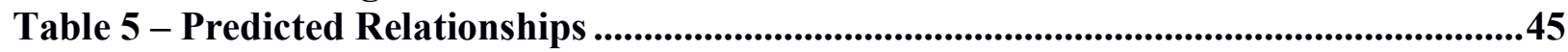




\section{List of Figures}

Figure 1. - Graph of moderation effect of PO Fit on the relationship between attachment anxiety and disidentification ................................................................................................................ 45 


\section{Introduction}

When asked the question "who am I?" the answer typically depends on the groups you believe you belong to. From simple traits like gender or race to membership in political parties or sports clubs, this web of traits is woven together to create your identity. While many types of group exist, organizations are a type of group that have garnered considerable academic attention. Organizational identification has been studied extensively in its positive effects on a variety of work related variables such as job satisfaction, turnover intent, performance and absenteeism (Riketta, 2005). Recently there has also been an increase in research on potential downsides of excessive amounts of organizational identification such as an increase in proorganization unethical behaviours (Avanzi, van Dick, Fraccaroli \& Sarchielli, 2012; Conroy, Henle, Shore \& Stelman, 2017). Some organizational identification theorists have argued that there are additional ways in which individuals can define themselves in terms of their organization beyond this unidimensional measure of identification (Dukerich, Kramer \& McLean Parks, 1998; Elsbach, 1999; Pratt, 2000; Kreiner \& Ashforth, 2004). This supposition lead to the development of an expanded model of organizational identification (Kreiner \& Ashforth, 2004), although it has since received essentially no further development. I argue that the use of this expanded model is justified and examine what leads an individual to identify with their organization in these different ways.

Previous research on the expanded model of organizational identification examined how a number of variables correlate with each type of identification as an exploratory look at the antecedents of the expanded types (Kreiner \& Ashforth, 2004). I argue that a similarly multidimensional construct will provide more insight to the origins of identification. Attachment 
theory (Bowlby, 1969; 1973; 1980), specifically attachment style in adulthood, will inform how individuals approach their relationship with an organization. I hypothesize that individuals with attachment styles that lead them to seek attention from others will be generally more likely to identify with their organization while those that tend to shun social connections will be less likely to do so.

In this paper I first review the literature on organizational identification, noting its grounding in theories of the self. In particular, I focus on the expanded definition of organizational identification proposed by Kreiner and Ashforth (2004) that centres on four separate ways an employee can identify with their organization. I will then review the literature on adult attachment theory and its recent developments and application to groups. I argue that adult attachment style will predict if and how employees identify with their organization. I will also examine the concepts of need for organizational identification and person organization fit and how they impact the relationship between attachment and identification.

I believe this paper offers a number of contributions. First, I provide support for the continued use and development of an expanded model of organizational identification. This is an area of the organizational identification literature that is sorely lacking theory on its antecedents and outcomes as well as empirical evidence to support its use. Furthermore, while there exists empirical research on groups as attachment figures (Smith, Murphy \& Coats, 1999) and theory that suggests that organizations can function as attachment figures (Grady \& Grady, 2013), I provide empirical evidence to extend and support the existing literature. I also extend both the organizational identification and attachment theory literature by examining how the constructs relate empirically in the work setting. 


\section{Identity in the Workplace}

Organizational identification is the social identity that an individual holds in their workplace. Employees are identified with their organization when they define themselves at least partially in terms of their organization (Kreiner \& Ashforth, 2004). Ashforth and Mael (1989) described organizational identification as a sense of "oneness" an employee has with their organization. Unlike other similar constructs such as person-organization fit or affective organizational commitment, identification is specific to the employee's current organization. An individual can perceive a fit with any organization with which they believe they have a sufficient amount of overlapping characteristics with, but cannot identify as a part of an organization they do not belong to. Organizational identification research has examined the benefits of the presence of employee identification (Riketta, 2005; Lee, Park \& Koo, 2015). The literature demonstrates the effect that organizational identification has on a variety of important outcomes such as improved job satisfaction (van Dick et al., 2004), performance (Lee, Park \& Koo, 2015) and reduced turnover intent (Conroy, Becker \& Menges, 2016). Recently scholars have also examined the possible negative effects of individuals with excessively high levels of organizational identification (Conroy, Henle \& Shore, 2017).

Shared among these papers is the assumption that individuals with an increasing amount of organizational identification will possess the traits associated with identifying and those with a lower amount of identification simply will not. A number of theorists have moved past this simplified view of organizational identification to suggest a number of different ways that an employee might relate to their organization in terms of identity (Dukerich et al., 1998; Kreiner \& Ashforth, 2004). Specifically, Kreiner and Ashforth (2004) describe the development of a more complex model of organizational identification due to the fact that the previous 
conceptualizations were limited to depicting organizational identification as the basic presence of shared values and goals.

In order to expand on the existing theories of organizational identification, Kreiner and Ashforth (2004) proposed three additional ways that employees can define themselves in relation to the organization - disidentification, ambivalent identification, and neutral identification. Disidentification exists when an employee defines their identity in terms of disagreement with the values they believe are core to the organization. For example, if an organization is perceived to value profitability an individual may disidenitfy with the organization by claiming to place little value on profit relative to other pursuits. Kreiner and Ashforth (2004) emphasize that disidentification is not simply a lack of identification. A disidentified employee actively rejects the values of the organization from their self-concept in order to preserve a positive social identity. While disidentified employees will be more likely to leave the organization, some may stay due to things like high salary, difficulty finding another position or strong normative or continuance commitment (Kreiner \& Ashforth, 2004).

Ambivalent identification occurs when an employee identifies with some aspects of the organization while disidentifying with others (Kreiner \& Ashforth, 2004). The existence of this type of identification is based on literature in social psychology which has demonstrated that people are able to accept both positive and negative aspects of a group and remain ambivalent without needing to resolve the conflict in one way or another (Thompson \& Holmes, 1996). An example of ambivalent identification is an employee who agrees with their organization's charitable donations but disagrees with their use of layoffs to cut costs. Not only can an employee be ambivalent about different aspects of the organization but they may also be 
ambivalent towards the same behaviour as it appeals to different values (Kreiner \& Ashforth, 2004). The employee that disidentifies with the use of layoffs as it harms the employees may identify with the pursuit of efficiency in the workplace.

The third proposed type of identification is neutral identification (Kreiner \& Ashforth, 2004). Neutral identification describes the lack of both identification and disidentification. In this case the employee neither agrees nor disagrees with the values of the organization, characterized by the individual who does not take sides and just does their work until it is time to leave. Elsbach (1999) theorized that neutral identification is not only the absence of identification and disidentification but a full identity, that of the loner or neutral arbiter. The employee is conscious of their low levels of identification, which then becomes an identity of neutrality or individuality in itself.

It is important to understand the benefits of positive identification in order to strive towards them and there exists substantial literature on the topic. However, the expanded model of organization addresses a much wider variety of potential self-definitions in the workplace that traditional organizational identification fails to address. Without a thorough understanding of other potential ways to derive an identity from organizational membership it becomes much more difficult to encourage identification as we do not know what is preventing it. As such it is also important to understand the antecedents of organizational identification in all its forms. In order to do so I argue that models of attachment should be examined in relation to organizational identification. Kreiner and Ashforth (2004) state that one of the defining characteristics of identification is that if an identified employee were forced to separate from their organization they would feel a "deep existential loss". This is similar to the way that the loss of significant 
relationships to individuals are experienced in attachment theory (Bowlby, 1969; 1973; 1980). I propose that the attachment styles of individuals in an organization can provide insight to how they form relationships with significant social objects and therefore how they form an identity based on their relationship with their organization.

\section{Attachment Theory}

Attachment theory was originally developed by psychologist John Bowlby in order to explain why infants remain close to a parent in situations that may present some amount of threat to their safety and the patterns of those interactions. In his trilogy on the subject, Attachment and Loss $(1969 ; 1973 ; 1980)$ Bowlby argued that infants must explore the world around them in order to learn and develop their abilities. This exploration can be dangerous for an infant and it is therefore important to have a guardian (attachment figure) in close proximity to go to for protection if a threat presents itself, be it a predator or fatigue. This attachment provides both physical and psychological security to the infant, providing a sense of safety and ability to rely on others, the attachment figure acting as a secure base from which to operate and develop (Bowlby, 1988). The quality and type of attachment is determined by the extent to which infants rely on their attachment figure for security, based on their experiences over time (Ainsworth, Blehar, Waters \& Wall, 1978). Bowlby (1969) argued that this attachment system is a product of evolution, best suited to human infants due to the long development period before children are able to reasonably protect themselves. While important in infancy, Bowlby believed that this attachment system remained active and regulated attachment behaviours with important others throughout adulthood (Bowlby, 1988; Ainsworth, 1989). 
Ainsworth (1978) later developed a laboratory method for determining the patterns of attachment of a given infant based on their behaviour in the presence of their attachment figure as well as after separation and reunion with the attachment figure, dubbed the strange situation. Ainsworth found three attachment patterns which she labelled secure, anxious-resistant and avoidant (Ainsworth et al., 1978). Secure infants sought out their attachment figure when threatened, were distressed when separated and pleased to be reunited. Anxious-resistant infants are concerned with their attachment figure's presence and are not comforted when they are reunited. Avoidant infants avoid their attachment figure altogether, occupying themselves with things in the environment. Slightly more than half of infants fall into the secure category, the remainder being split between avoidant and anxious-ambivalent, with the avoidant group being slightly larger (Ainsworth et al., 1978).

Attachment theory states that infants internalize their experiences of having sought comfort from their attachment figure, creating a framework for later social interactions with other potential attachment figures (Bowlby, 1973). The two aspects that form this framework are "(a) whether or not the attachment figure is judged to be the sort of person who in general responds to calls for support and protection; (b) whether or not the self is judged to be the sort of person towards whom anyone, and the attachment figure in particular, is likely to respond in a helpful way" (Bowlby, 1973, p.204). These two aspects describe the individual's model of others and model of the self, respectively. These models remain relatively consistent into adulthood and have been shown to continuously produce similar behaviour in adulthood (Bartholomew \& Horowitz, 1991). 
Bringing attachment theory to an adult context, Shaver and Hazan (1987) examined romantic partners as attachment figures. They developed a self-report measure in which participants self-selected which of the three attachment types described them best based on a paragraph describing them. They found that their self-selection sample mirrored the rates of infants in each category, with $56 \%$ being secure, $25 \%$ avoidant and $19 \%$ anxious-ambivalent (Shaver \& Hazan, 1987). The insecure groups reported higher rates of negativity about love, shorter romantic relationships and provided more negative descriptions of their parents during their childhood (Shaver \& Hazan, 1987).

Bartholomew and Horowitz (1991) later observed that despite attachment theory being based on models of the self and other, studies such as those by Shaver and Hazan (1987) had focused on the three types of attachment identified by Ainsworth (1978). Bartholomew and Horowitz (1991) argued that by dividing the models of self and other into positive and negative categories and crossing them, four categories should be found. The model of self describes whether an individual believes they are deserving of attention, a positive evaluation meaning they deserve it and a negative evaluation indicating that they believe they are undeserving. The model of others describes if an individual believes that other people will help them when they are in need of assistance. A negative evaluation meaning the individual views others as unresponsive in times of need, a positive evaluation indicating that the individual believes that others will respond to calls for assistance. They proposed a four-category model of adult attachment, suggesting that adults can experience secure, preoccupied, dismissing and fearful attachment. Secure individuals have a positive model of both the self and others, believing they are both deserving of attention and others will respond when called on. Preoccupied individuals have a 
positive model of others but a negative model of the self, being highly dependent on others for approval and validation. They believe that others are responsive to calls for help but that they are not deserving of attention. Dismissing individuals have a positive model of self and negative model of others, downplaying the importance of interpersonal relationships and placing an emphasis on independence. They believe that they are deserving of attention but that others will not respond when they are in need. Finally, fearful individuals have negative models of both the self and others, believing that they are not deserving of attention and that others are unavailable to them. Bartholomew and Horowitz (1991) label the two axes as "avoidance of intimacy" and "dependence"; the secure and dismissing groups are similar in that they have a positive selfimage that is maintained internally rather than depending on others. They are different in that the dismissive group avoids intimate relationships with attachment figures while the secure group is able to develop intimate relationships actively (Bartholomew \& Horowitz, 1991).

Based on this work, as well as others working on similar measures, Brennan, Clark and Shaver (1998) completed a factor analysis of all available self-report measures for adult attachment style, a total of 323 items given to over 1,000 participants. They found that there were indeed two independent dimensions, which they labelled Anxiety and Avoidance, keeping the 18 most highly related items on each of the two factors to create the Experiences in Close Relationships Scale (ECR; Brennan et al., 1998). They defined Attachment Anxiety as the fear of rejection or abandonment by their attachment figure, constant need for external approval and distress if the attachment figure is not in close proximity or supportive (Brennan et al., 1998). Attachment avoidance describes a fear of having to depend on others or become intimate, fierce 
need for independence and resistance to speak about their personal experiences (Brennan et al., 1998).

As previously mentioned, it is a tenet of attachment theory that the attachment behaviours and styles remain relevant throughout adulthood (Ainsworth et al., 1978; Bowlby, 1969). Attachment anxiety and avoidance measures have been found to be positively related to poor coping abilities (Wei, Heppner, Russell \& Young, 2006), personal problems (Lopez, Mitchell \& Gormley, 2002) and depression (Zakalik \& Wei, 2006). Additionally, Hazan and Shaver (1990) found relationships between adult attachment style and a variety of work related outcomes and attachment theory in the work context has been given considerable attention in recent years (Yip, Ehrhardt, Black and Walker, 2018). The majority of recent research is concerned with relationship formation between coworkers, and organizational outcomes such as productivity (Wu \& Parker, 2017) and problem solving (Mikulincer, Shaver \& Rom, 2011). Lacking attachment figures and social support in the work context has also been linked to negative outcomes for employees such as work related strain (Schirmer \& Lopez, 2001; Harms, 2011).

While attachment theory began with the relationships between infants and their guardians it has expanded considerably to encompass a variety of attachment figures throughout the lifetime. One such expansion regards the use of groups as attachment figures. Group attachment was introduced by Smith et al. (1999) to address how individuals view themselves as group members and their internal models of groups. Despite the group being a part of the relationship it is important to note that group attachment is not a group-level variable. It is an individual-level construct as the individual experiences attachment to the group (Yip et al. 2018). Rom and Mikulincer (2003) found support for the use of groups as attachment figures as participants 
related to their groups following the same patterns as they did with human attachment figures. Participants high in anxiety sought validation from the group while avoidant participants sought independence from the group. Rom and Mikulincer (2003) found unique moderators for groups as attachment figures such as group cohesion. While there may exist different situational factors that can impact how attachment style influences group-related outcomes, the literature shows support for groups as attachment figures (Smith et al., 1999; Rom \& Mikulincer, 2003; Lee \& Ling, 2007).

Building on the group attachment literature, two recent papers have examined organizations as attachment figures. Both are theoretical in nature but support the pursuit of more empirical work on the subject. Grady and Grady (2013) theorized that organizational change acts as a type of separation from the attached organization in which the responses to threats are guided by attachment style. Albert, Allen, Biggane and Ma (2015) proposed that individuals will react to the termination of their employment relationship similarly to how they would react to the end of other relationships with attachment figures such as romantic partners. Ashforth, Schinoff and Brickson (in press) examine one potential mechanism for how organizational members come to see their organization as an attachment figure. They argue that organization members anthropomorphize their organization, viewing it in terms of "who" it is instead of "what" it is. They propose that this occurs from the top-down as organizational agents present the organization as a living being to the members, as well as from the bottom up as members ascribe human traits to the organization. This serves to reduce uncertainty in interacting with the organization, allowing organizational members to form social relationships with their anthropomorphized organization (Ashforth et al., in press). These theoretical contributions 
support the continued development of attachment as it relates to organizations, especially empirical work to support the theory.

I propose that an individual's adult attachment style will inform not only their reactions to changes in the employment relationship, but also how they approach the organization as a social object. In this case I will be examining how attachment style relates to organizational identification. The two factors that determine attachment style are attachment anxiety and avoidance (Brennan et al., 1998). When examining the relationship between attachment and organizational identification it is important to look at the pattern of relationships with both attachment anxiety and avoidance in order to meaningfully interpret the results. As such I will propose a pattern of relationships for each identification type.

Preoccupied individuals are high in attachment anxiety and low in avoidance; they are excessively dependent on others to provide them with reassurance and positive feedback, leaving them constantly concerned with their relationships (Brennan et al., 1998). In the organizational context, high levels of attachment anxiety are shown to be positively related to requests for feedback (Wu, Parker \& de Jong, 2014). Highly anxious individuals look to the organization to provide them with reassuring feedback as they would in a significant relationship with an individual. Based on this I hypothesize that preoccupied individuals will be more likely to identify with an organization as their behaviour pattern involves an obsessive preoccupation with their relationships (Bartholomew \& Horowitz, 1991). The relationship with the organization provides highly anxious individuals with an opportunity to receive positive, reassuring feedback. Hypothesis 1a: Organizational identification is positively related to attachment anxiety. Hypothesis $1 \mathrm{~b}$ : Organizational identification is positively related to avoidance. 
The fearful attachment group is comprised of those high in both anxiety and avoidance behaviours (Bartholomew \& Horowitz, 1991). Fearful individuals have negative models of themselves as unworthy of the attention of others, and of others who they believe will reject and abandon them (Bartholomew \& Horowitz, 1991). As in all of their relationships, fearful people are typically distrustful of agents of the organization (Albert \& Horowitz, 2009). However their desire for positive feedback from others due to their attachment anxiety results in a highly conflicted and frustrating dynamic in which they reject the intimacy they so desperately desire (Simpson \& Rholes, 2002). I suggest that the fearful group will be more likely to disidentify as it provides them a means to define themselves in relation to their organization but maintains a high level of emotional and psychological distance, partially satisfying their anxious and avoidant needs.

Hypothesis 2a: Disidentification is positively related to attachment anxiety.

Hypothesis 2b: Disidentification is positively related to avoidance.

As Kreiner and Ashforth (2004) note, ambivalence correlates positively with disidentification and negatively with identification. Theoretically ambivalence should be correlated positively with both but in previous research this is not the case (Kreiner \& Ashforth, 2014). It may be the case that for an average employee the "default" stance to take towards the organization is one of mild identification (Ashforth \& Kreiner, 2004). This means that any admission of disidentification, however mild, is a strong step away from identification. As such, individuals high in ambivalent identification should show similar patterns as those high in disidentification.

Hypothesis 3a: Ambivalent identification is positively related to attachment anxiety. 
Hypothesis 3b: Ambivalent identification is positively related to avoidance.

Individuals high in neutral identification will most likely fall into the dismissive archetype. These individuals believe that attachment figures are unavailable to them and seek independence whenever possible. In regards to their identity in reference to their organization they will avoid defining themselves in those terms altogether. To identify with the organization is to become intimate with a social object, something a dismissive individual will try and avoid.

Hypothesis $4 a$ : Neutral identification is negatively related to attachment anxiety.

Hypothesis $4 b$ : Neutral identification is positively related to avoidance.

Although an individual's attachment style will predict their organizational identification, it is likely that other aspects of their perception of the organization will interact with attachment to influence organizational identification. Specifically, I will focus on two constructs that may moderate the relationship between attachment and identification: the need for organizational identification and person-organization fit. Glynn (1998) proposed the use of a concept called need for organizational identification (nOID). nOID is a trait that describes the extent to which an individual is predisposed to identification with social groups (Glynn, 1998). She argues that nOID is positively related to membership with social groups and negatively related to individualism in the social context. Person-organization fit (PO fit) can be broadly defined as the level of compatibility between an individual and an organization (Kristof, 1996). It can be broken down into two prominent types therein: objective and subjective fit (Ubershaer, Baum, Bietz \& Kabst, 2016). 


\section{Moderators of Attachment and Organizational Identification}

Kreiner and Ashforth (2004) examined nOID as an antecedent of the expanded model of organizational identification and found it to be strongly positively related to identification and negatively related to neutral identification and moderately negatively related to ambivalent identification and disidentification. Individuals with a high level of nOID are more willing to incorporate their membership in their organization into their individual identity, treating their relationship with their organization as they would a relationship with a significant person in their lives. If the individual is predisposed to treat the organization as they would a human attachment figure, the individual's attachment style then informs how the relationship takes form.

Conversely, people with a low level of nOID are unwilling or do not see the need to include their organization in their personal identity. They do not treat the organization as an attachment figure and therefore the individual's attachment style is not relevant in the formation of their organizational identity. This only applies to identification because nOID is framed in positive terms. Measurement of nOID focuses on whether or not the individual reports that they generally would like to be thought of as a representative of their organization, a positive way of deriving identity from the organization. While disidentification and ambivalent identification are both ways to derive an identity from organizational membership individuals with these traits will report a low level of nOID due to the negative way in which they relate to the organization. Based on this I propose that nOID will moderate the relationship between attachment anxiety and identification. High levels of nOID and high levels of attachment anxiety will be positively related to organizational identification. A high level of nOID and a low level of avoidance will also be positively related to organizational identification. A low level of nOID will result in attachment anxiety and avoidance being unrelated to organizational identification. 
Hypothesis 5: Need for organizational identification and attachment will interact to influence organizational identification. The relationship between attachment and organizational identification is stronger when need for organizational identification is high than when it is low.

Objective PO fit is a measure of fit obtained by creating a list of characteristics of an organization and comparing them to those of an individual. Subjective PO fit is the perceived level of compatibility by an individual with regards to an organization (Ubershaer et al., 2016). PO fit is distinct from organizational identification in two important ways, the first being the integration into the self-concept. Organizational identification requires an individual to incorporate their organizational membership into their self-concept. PO fit involves identity in that the individual compares their characteristics to those of the organization to determine their level of fit but it does not involve defining yourself in those terms. The second main difference is the specificity to the current organization. Individuals can engage in a process of comparison and assess their perceived fit with any organization, as long as they know the organization's characteristics. Organizational identification is to define yourself in terms of organizational membership, which cannot take place with an organization you do not belong to. Due to these differences PO fit provides an additional perspective on how the employee views the organization and relate to it. PO fit is positively related to job satisfaction, organizational identification and reduced turnover intent (Edwards \& Cable, 2009). In this case I hypothesize that higher levels of PO fit will allow employees to engage with the organization, encouraging them to integrate the organization into their identities. Negative experiences with the organization are made more impactful if the employee perceives the organization to have broadly 
similar characteristics to their own ( $\mathrm{Lv} \& \mathrm{Xu}, 2018$ ). Low levels of PO fit will lessen the impact of an employee's attachment style as they are less likely to define themselves in terms of the organization overall. This relationship will not exist for the dismissive attachment group as they will be neutral regardless of their level of PO fit.

Hypothesis 6: Person-organization fit will interact with attachment to influence organizational identification, disidentification and ambivalent identification. The relationship between attachment and organizational identification, disidentification and ambivalent identification will be stronger when PO fit is high than when it is low.

\section{Method}

\section{Participants and Procedure}

Participants were recruited from Prolific, an online crowdsourcing platform based in Oxford University, through which they were given access to the online questionnaires. The study was a time-lagged design in which there were two time points. Participants who successfully completed the questionnaire at Time 1 were contacted again to complete the second questionnaire at Time 2. The questionnaire at Time 1 included measures of nOID, PO fit and adult attachment style. The questionnaire at Time 2 included measures for organizational identification, disidentification, ambivalent identification, and neutral identification. All measures were randomized to control for order effects. All participants were given $£ 0.50$ per survey in appreciation of their participation.

A total of 404 working adults participated in the study at Time 1. One participant had more than 5\% missing data, twelve participants failed attention checks, and one participant provided incomplete contact information. These participants were excluded from analysis. Three 
hundred and ninety participants were recruited to participate at Time 2, of whom 372 responded (95\% response rate). Ten participants had more than 5\% missing data and were removed from the data set. In total 362 participants completed the study at both points in time and remained in the final data set. Examination of the data showed that, as required, all participants were employed. All participants were from North America (88\% United States, 12\% Canada). Approximately $60 \%$ of participants were male and $72 \%$ were Caucasian. The average age of participants was $34.7(\mathrm{SD}=8.9)$, and a wide variety of industries were represented including hospitality, finance, health care and information technologies. The majority of participants had a university degree, graduate degree or college certificate (91\%).

\section{Measures}

NOID. Participants completed a 7-item measure of NOID to assess their desire to have an organization to identify with (Kreiner \& Ashforth, 2004). All items are measured on a 5-point Likert-type scale. A sample item is "Without an organization to work for, I would feel incomplete." $(\alpha=.82)$.

Attachment Style. Participants completed a 36-item scale that measures both attachment anxiety and avoidance created by Brennan, Clark \& Shaver (1998) and modified by Richards and Schat (2011) for use in an organizational context. All items are measured on a 7-point Likerttype scale. A sample item for attachment anxiety is "I worry about being rejected or abandoned", a sample item for attachment avoidance is "I find it difficult to allow myself to depend on close others" ( $\alpha=.94$ attachment anxiety, $\alpha=.94$ avoidance) .

Organizational Identification. Participants completed four 6-item scales that assess identification, disidentification, ambivalent identification and neutral identification. All items 
were measured on a 5-point Likert-type scale. The items for identification were developed by Mael \& Ashforth (1992) and a sample item is "When someone criticizes my organization, it feels like a personal insult" $(\alpha=.85)$. The remaining three scales were developed by Kreiner $\&$ Ashforth (2004). A sample item for the disidentification scale is "I am embarrassed to be a part of this organization" $(\alpha=.89)$. A sample item for the ambivalent identification scale is "I have mixed feelings about my affiliation with this organization" $(\alpha=.91)$. A sample item for the neutral identification scale is "This organization doesn't have much personal meaning to me" ( $\alpha$ $=.91)$.

Person-Organization Fit. Participants completed a three item measure of their perception of the extent to which their values match those of their organization (Cable \& Judge, 1996). The scale is measured on a 5-point Likert-type scale. A sample item is "My values match those of the current employees in this organization" $(\alpha=.93)$.

\section{Results}

Means, standard deviations, coefficient alphas and correlations for the eight measured variables can be found in Table 1 . Overall the variables are significantly correlated with one another. The negative correlations between identification and ambivalent and neutral identification are expected but conceptually interesting which will be covered further in the discussion. Analyses were also run controlling for participant age and sex. These variables did not affect the significance or interpretation of the results and will not be discussed further.

Hypotheses 1 through 4 were analyzed using multiple regression based on the recommended methods for the analysis of the ECR (Fraley \& Waller, 1998). Each identification scale was entered into a regression with the mean scores for attachment anxiety and avoidance in 
order to analyze them in a continuous fashion and interpret the two factors' influence on the outcome. Hypothesis 1a predicted a positive significant relationship between organizational identification and attachment anxiety, and Hypothesis $1 \mathrm{~b}$ predicted a negative significant relationship between organizational identification and avoidance. The predicted relationships with anxiety $(b=.10 ; p<.05)$ and avoidance $(b=-.15 ; \mathrm{p}<.01)$ were both supported. Hypothesis 2a predicted a significant positive relationship between disidentification and attachment anxiety and Hypothesis $2 \mathrm{~b}$ predicted a significant positive relationship between disidentification and avoidance. The predicted relationships were supported with anxiety $(b=.16 ; p<0.01)$ and avoidance $(\mathrm{b}=.14 ; \mathrm{p}<0.01)$. Hypothesis 3 a predicted a significant positive relationship between ambivalent identification and attachment anxiety and Hypothesis $3 \mathrm{~b}$ predicted a significant positive relationship between ambivalent identification and avoidance. The predicted relationships were supported for both anxiety $(b=.22 ; p<.01)$ and avoidance $(b=.14 ; p<.05)$. Hypothesis 4a predicted a significant negative relationship between neutral identification and attachment anxiety and Hypothesis $4 \mathrm{~b}$ predicted a significant positive relationship between neutral identification and avoidance. Hypothesis $4 \mathrm{~b}$ was supported; the relationship with avoidance was significant $(b=.16 ; \mathrm{p}<.01)$ but Hypothesis 4a was not supported, the relationship with anxiety was not significant $(b=.06 ; \mathrm{p}>.05)$.

Hypotheses 5 and 6 were tested with hierarchical multiple regression using SPSS. The predictor variables (attachment anxiety, avoidance, PO fit and nOID) were all mean centered in order to reduce multicollinearity in the analysis. Four interaction terms were created from the centered variables, two for each hypothesis. The interaction effects were created by multiplying the attachment variables with the moderator variables e.g. avoidance X nOID. Attachment 
anxiety and avoidance were entered into the first block of the regression followed by nOID or PO fit in block two and their respective interaction effects in block three.

Hypothesis 5 predicted a significant interaction between attachment anxiety and nOID and avoidance and nOID. Hypothesis 5 was not supported as there were no significant relationships between the interaction effects including nOID and anxiety $(b=.00 ; p>.05)$ nor for nOID and avoidance $(b=-.08 ; p>.05)$. Hypothesis 6 predicted a significant interaction between attachment anxiety and PO fit and avoidance and PO fit. Only one significant interaction effect was found for PO fit and attachment anxiety on disidentification $(b=.08 ; p<$ 0.05; see Figure 1). This interaction demonstrated that individuals low in PO fit had the same level of disidentification regardless of their level of anxiety. For individuals high in PO fit anxiety correlated positively with disidentification. None of the other interactions reached significance and minimal support was found for Hypothesis 6 (see Tables 3 and 4).

\section{Discussion}

Attachment theory has received increasing attention in recent years, notably in the context of organizations. Work related outcomes affected by attachment style have received considerable attention in the literature, however there has yet to be research on the effects of attachment style on organizational identification. This presented an opportunity to make use of and evaluate the expanded model of organizational identification, which has had a paucity of research dedicated to it since its inception. This study expands the literature for both attachment theory as well as that of organizational identification. While there are issues with its current implementation, the results of my research provide support for continued research on and development of the expanded model of organizational identification 
Overall, the hypotheses related to attachment style and organizational identification were largely supported.. As predicted, organizational identification is related to attachment anxiety positively and related to avoidance negatively. This pattern of relationships suggests that, according to Bartholomew's (1991) prototypes, employees falling into the preoccupied group are the most likely to identify with their organization followed by the fearful and secure groups with dismissive employees being the least likely to identify. The empirical results support the idea that anxious individuals can and do look to their organization for external validation similarly to how they conduct themselves with other individuals. The lack of felt security experienced by more anxious individuals drives them to identify with social groups in the continued pursuit of external sources of self-enhancement.

As theorized, disidentification was positively related to both attachment anxiety and avoidance. Again looking at Bartholomew's (1991) prototypes this means that fearful employees are most likely to be disidentified, followed by preoccupied and dismissive employees, with secure employees being least likely to disidentify. Fearful individuals experience both the need for external validation from others as well as the fear of dependence on others that preoccupied and dismissive individuals typically experience separately. Unlike the dismissive group, they require external reassurance to maintain a positive self-image, guiding them to define themselves in terms of their relationship with the organization. But in contrast with the preoccupied group, the fearful employees do not feel comfortable being vulnerable or intimate by forming an attachment relationship and defining themselves positively in terms of their organizational membership. This approach-avoidance conflict may be what leads them instead to disidentify 
with the organization, allowing for an external relationship to form but maintaining a type of emotional distance from the other members and the organization itself.

Ambivalent identification follows the same pattern of relationships as disidentification. Although ambivalence is theoretically the mixture of identification and disidentification, the default state of any organizational member is likely some amount of identification. For an employee to report strong negative feelings about their organizational membership, even in part, they are likely already much closer to disidentification than identification. This is also one issue with the way the expanded model of organizational identification is measured, discussed further below.

As predicted, neutral identification is related to avoidance positively. However, contrary to expectations, neutral identification is unrelated to attachment anxiety. This means that dismissive and fearful individuals are equally likely to be neutrally identified followed by the secure and preoccupied groups. This pattern of results indicates that the more avoidant you are the more likely you are to be neutral, regardless of attachment anxiety. This is complicated by the fact that neutral identification is positively correlated with disidentification and ambivalent identification despite it being theoretically the opposite. This may again be due to the fact that identification is more of a default stance for individuals to take with a neutral identity being more negative than it is given credit for in practical situations, as well as due to how identification is measured.

Contrary to expectations, employee nOID did not moderate the relationship between attachment style and identification. While I had hypothesized a moderated relationship, it may be instead that nOID mediates the relationship between attachment and identification. An 
individual's attachment style may lead them to develop more or less of a propensity for identification with social objects rather than these being unrelated characteristics within individuals. Anxious individuals require external sources of validation and support, a need that develops in childhood. It follows that individuals that look to attachment figures to provide them with a more positive self-image develop a higher level of need to have social objects define them. Both individuals and social objects such as the organization serve as external sources of attention for anxious individuals to look to for attention. In contrast, individuals high in avoidance dismiss the need for intimacy with attachment figures, at the most extreme becoming pathologically self-reliant. Highly avoidant individuals are independent and do not see attachment figures in general as important aspects of themselves and would therefore not report a high level of nOID. Preoccupied individuals would likely report the highest level of nOID and dismissive the least with secure and fearful falling somewhere in between. Considering nOID's strong zero-order correlations with identification this relationship may provide a high amount of explanatory power and merits further research on the subject.

I found little support for the theorized relationships between attachment, PO fit, and identification. With the exception of exception of the relationship between attachment anxiety and disidentification, PO fit did not moderate any of the paths between attachment and identification. The pattern of the interaction suggests that the relationship between attachment anxiety and disidentification is stronger when PO fit is high. Despite this, the lack of general support for this hypothesis provides little in the way of meaningful results. One difficulty in the use of PO fit is that it is subjective and continually reevaluated by the individual (Ubershaer et al., 2016). While individuals may have perceived a high level of PO fit at the onset of their 
tenure with the organization, even one negative experience may lead them to assign new negative characteristics or change existing positive characteristics to reflect their experience. This in turn changes the level of subjective PO fit. Furthermore, attachment styles can lead employees to interpret events more or less negatively (Schmidt, 2016) which can lead to lower reported levels of PO fit. This may be one path between attachment and identification in which it is mediated by perceived negative events and PO fit. This may be a spurious relationship as a higher level of perceived negative events at work leads to lower levels of identification, higher levels of disidentification and lower levels of PO fit rather than PO fit being directly related to identification or disidentification. Further research may clarify the nature and direction of these relationships.

Overall, this research does provide support for an expanded model of organizational identification. There exist three distinct patterns of relationships between attachment style and organizational identification, two of which are missed entirely when examining only positive identification as is often the case in the literature. In research examining only positive identification the results would show that individuals high in attachment anxiety and low in avoidance are most likely to identify. This does not account for the unique ways in which fearful and highly avoidant individuals relate to their organizations. Failing to account for a factor of identification is akin to examining attachment while only measuring avoidance and ignoring anxiety altogether. However, the current method for the assessment of the expanded model of organizational identification has some issues that must be addressed if it is to be adopted on a larger scale in the field. The main issue in the use of the expanded model of organizational identification is the use of four separate scales to assess an individual's identification. In theory 
there exist two factors in the expanded model: identification and disidentification. Identification is commonly studied and disidentification is introduced to account for ways in which employees define themselves in terms of their separation from the organization (Kreiner \& Ashforth, 2004). Crossing these two factors results in a four-category model comprised of identification, disidentification, ambivalent and neutral identification based on an individual's scores on the two factors plotted in a two dimensional space. This is the essentially the same way that attachment style is conceptualized and it follows that organizational identification should be measured the same way as well. One scale each for identification and disidentification would allow for organizational identification to be analyzed in a continuous fashion and interpreted into general categories as the theory would dictate. However, Kreiner and Ashforth (2004) developed three additional scales to be used alongside the existing measures of identification with one for each of the categories which has resulted in some difficulties in the interpretation of results.

One of the main issues with the use of four ostensibly discrete scales is that the categories are moderately to highly correlated. Disidentification and ambivalent identification are the two most highly related categories as is visible in the zero-order correlations in Table 1 . Theoretically each category is highly similar on one of the two categories and differentiated by the other (e.g. identified and neutral are both low in disidentification but differentiated by the level of identification). An individual should therefore belong loosely to only one category based on their scores on the two factors. In practice, individuals report at least some level of belonging to all four categories when presented with the four scales. This makes interpretation of results more difficult as individuals should not be simultaneously neutral and ambivalently identified, they should be polar opposites. If they should be related to one another as dictated by the underlying 
theory they should be measured as two factors, scales for ambivalent and neutral identification would be made redundant. Relationships between categories are unimportant as they serve only to further interpretation of the results, the factors themselves being continuous.

While I maintain that the categorical measurement of the expanded model of organizational identification is problematic, the relationships may provide some insight into the antecedents for category membership. Both ambivalent and neutral identification measures correlate positively with disidentification despite their theoretical differences and linguistic differences in the items themselves. That being said, ambivalent and disidentification share a stronger relationship than with neutral identification which suggests that they have a considerable overlap. As Kreiner and Ashforth (2004) discuss in their initial examination of the expanded model, it may be the case that the default stance of any employee is some level of identification. Therefore when individuals defines themselves, even in part, based on their separation from the organization they are already much further from their organizational identity than the average employee.

Organizational identification is highly negatively related to neutral identification, as shown in Table 1. The relationship is considerably stronger than between identification and disidentification or ambivalent identification, despite disidentification being the theoretical opposite of identification. This may suggest that despite the change in the valence of the relationship, identification and disidentification are similar in that both groups derive their identity from membership in the organization. Individuals in these groups may be more willing to move between identified, disidentified and ambivalently identified than they are to define themselves wholly in their own terms. This makes neutral identification quite unique compared 
to the other groups; it is possible that neutrally identified individuals have a stronger, more stable sense of self in order to rely on it over a socially derived identity.

The results also provide support for the continued use of attachment theory in the study of the employee-organization relationship. Specifically the results show that organizational identification is influenced by employee attachment style. This also supports some of the theoretical work on organizations as attachment figures (Grady \& Grady, 2013; Albert et al., 2015 ) in that employee attachment style is applied to organizational membership as it would to other attachment figures. This is promising as the literature in the area continues to develop alongside that of group attachment dynamics.

\section{Limitations and Future Research}

Theoretical contributions notwithstanding, there are a number of limitations to this study. First is that the expanded model of organizational identification has had very little development beyond the initial exploratory paper in which it was introduced. It is important to bear in mind that these results provide support for a model of organizational identification beyond the typically used a one-factor model but do not demonstrate definitive support for this model in its current form or currently proffer a substantive replacement. One of the most useful studies to conduct going forward would be to conduct a latent profile analysis to examine how results from the current four scales cluster in order to continue to refine the model and change the scales to reflect the results. Although the current model is an excellent first step it is clear based on the results of this study that substantial development remains before widespread adoption can take place. The creation of discrete profiles would also serve to eliminate many of the issues in the use of the expanded model previously discussed. 
The second issue is that there may be cyclical interactions between identification and related variables such as PO fit and nOID that restrict the interpretation of their relationships. For the most part nOID is addressed as an antecedent to organizational identification in which individuals with a high need are more likely to identify. It may be the case that individuals with low levels of identification report low levels of nOID because the alternative is threatening to their self-concept. A disidentified individual may feel discomfort reporting that they wish to be able to incorporate their organization into their identity. Doing so puts them in a situation where they say it is important to them to identify but that they currently do not. To resolve this conflict they may instead justify their disidentification by reporting a low level of nOID (i.e. "I do not have it, therefore I do not need it).

These issues surrounding causality in the relationships are a limitation caused by the cross-sectional and self-report methodology of this study. The self-report methods are an important part of both attachment theory and identification research as both are dependent on individual perception of themselves and their organization and cannot be arrived at objectively. Concerning causality and directionality concerns in the study, future studies can address this definitively through the use of longitudinal methods. However, this is not likely to produce meaningfully different results as attachment styles are trait based (Bowlby, 1969; 1973; 1980; Ainsworth, 1989).

As both of the proposed moderators of the relationships between attachment and organizational identification failed to reach significance, it would serve well to continue to examine how the two constructs relate to one another. While nOID may function as a mediator between attachment style and organizational identification it is also important to examine others 
such as perceived psychological contract breach or responses to threatening events such as downsizing events. Highly anxious individuals may respond to threatening events by seeking reassurance even more intensely in order to avoid the loss of their attachment to the organization as anxious individuals consider abandonment by an attachment figure a highly negative experience. This may in turn lead to a stronger incorporation of the organization into the individual's identity in order to demonstrate that they belong in the organization. Highly avoidant individuals respond less negatively to separation events, they expect attachment figures to be unresponsive to their needs. This would likely serve to reinforce their avoidance of intimacy with attachment figures in the future. The expansion of our understanding of the mechanisms of action between attachment and organizational identification can assist us in understand both constructs more fully as well as their place within the nomological network in which they exist.

One construct that may moderate the relationships between attachment and organizational identification is anthropomorphism. Individuals who anthropomorphize their organization, or are more likely to anthropomorphize non-human social objects in general, may be more likely to react based on their attachment style when the employee-organization relationship is threatened. A state based measure of anthropomorphism of the current organization will likely serve as a stronger moderator than one of trait based propensity to anthropomorphize in general as anthropomorphism is also likely effected by how agents of the organization portray it to members. Organization specific traits such as organizational culture or how work is conducted (e.g. in open office plans or telecommuting) may also moderate the relationship between attachment and organizational identification. 
Another potential line of research would be the mediation of the relationship between attachment style and organizational identification through an attachment to an agent of the organization such as a manager or supervisor. While the group attachment literature has demonstrated that individuals can attach to groups directly, it may be the case that attachment to an organizational agent leads to the attachment style influencing other work related outcomes such as organizational identification. This may take place as employees treat the agent as if they were the organization or the organization as if they were the agent. That is to say, employees may think of the manager that they see as an attachment figure when asked about the organization and base their responses off of how they feel about this individual. In this case they do not see the organization itself as an attachment figure and the relationships between attachment and work related outcomes are likely fully mediated by attachment to this organizational agent. In the other case, the employee treats the relationship with the organization the same as they do with their manager. The relationship with the organizational agent is generalized to apply to the organization itself and the employee views both the agent and the organization itself as attachment figures. In this case I would expect mediation of the relationship between attachment and organizational identification.

In addition, it would be useful to study the relationship between attachment and organizational identification within an organization in order to provide a strong context for interpretation of results. Attachment style can impact how events are perceived and responded to by employees in an organization (Schmidt, 2016). Providing a contextual study in which all employees experience objectively similar events within the organization could provide considerable insight into how these employees identify based on their attachment styles. 
There also exists considerable research on the outcomes of organizational identification, both positive and negative (e.g. Conroy et al., 2017). There is essentially no research on the outcomes of the expanded types of organizational identification. Theory on the model suggests that there will be substantially different outcomes for the four categories (Dukerich et al., 1998; Kreiner \& Ashforth, 2004) and as such it will be very important to research them extensively.

Overall I propose four main paths for future research on organizational identification. The first and foremost is the latent profile analysis of the four scales of the expanded model of organizational identification. This will allow for a fuller understanding of how many distinct identification groups there are in practice rather than only those derived from theory. The second is the mechanisms of action between attachment styles and organizational identification. Both attachment to organizational agents and nOID provide potentially fruitful lines of research both in theoretically and empirically as mediators. The third is potential moderators of the relationships between attachment and organizational identification. Employee anthropomorphism of the organization and a variety of organization specific traits such as organizational culture could potentially serve as moderators of these relationships. Finally, there is essentially no literature on the outcomes of the expanded types of organizational identification. While this step may be better off left after the model itself is developed somewhat further, it is difficult to speak to the practical effects of the expanded model types without understanding their outcomes.

In this paper I examined the influence that adult attachment style has on organizational identification. Three distinct patterns arose between attachment and organizational identification which demonstrate the unique ways in which both attachment anxiety and avoidance impact social identity in the workplace. Generally attachment anxiety promotes self-definition in terms 
of the organization regardless of valence. Avoidance promotes the maintenance of emotional distance from the organization. These empirical contributions provide support for and the extension of the current literature on adult attachment style in an organizational context as it has been predominantly theoretical. Furthermore, I have provided support for an expanded model of organizational identification that takes into account additional ways that individuals may derive an identity from their organizational membership beyond that of a positive representative of the organization. Finally I suggest further research on the profiles underlying the current scales of organizational identification as well as the mechanism through which attachment relates to identification. 


\section{References}

Ainsworth, M. D. S. (1989). Attachments beyond infancy. American Psychologist, 44, 709-716.

Ainsworth, M. D. S., Blehar, M. G, Waters, E., \& Wall, S. (1978). Patterns of attachment: A psychological study of the strange situation. Hillsdale, NJ: Erlbaum.

Albert, L. S., Allen, D. G., Biggane, J. E., \& Ma, Q. (Kathy). (2015). Attachment and responses to employment dissolution. Human Resource Management Review, 25(1), 94-106.

Albert, L. S., \& Horowitz, L. M. (2009). Attachment Styles and Ethical Behavior: Their Relationship and Significance in the Marketplace. Journal of Business Ethics, 87(3), $299-316$.

Ashforth, B. E., Harrison, S. H., \& Corley, K. G. (2008). Identification in Organizations: An Examination of Four Fundamental Questions. Journal of Management, 34(3), 325-374.

Ashforth, B. E., \& Mael, F. (1989). Social Identity Theory and the Organization. The Academy of Management Review, 14(1), 20-39.

Ashforth, B. E., Schinoff, B. S., \& Brickson, S. L. (in press) "My Company is Friendly," "Mine's a Rebel": Anthropomorphism and Shifting Organizational Identity from "What" to "Who". The Academy of Management Review, 1-66.

Avanzi, L., van Dick, R., Fraccaroli, F., \& Sarchielli, G. (2012). The downside of organizational identification: Relations between identification, workaholism and well-being. Work \& Stress, 26(3), 289-307.

Bartholomew, K., \& Horowitz, L. M. (1991). Attachment styles among young adults: A test of a four-category model. Journal of Personality and Social Psychology, 61(2), 226-244. 
Bowlby, J. (1969). Attachment and loss: Vol. 1. Attachment. New York: Basic Books.

Bowlby, J. (1973). Attachment and loss: Vol. 2. Separation: Anxiety and anger. New York: Basic Books.

Bowlby, J. (1980). Attachment and loss: Vol. 3. Sadness and depression. New York: Basic Books.

Bowlby, J. (1988). A secure base: Clinical applications of attachment theory. London: Routledge.

Brennan, K. A., Clark, C. L., \& Shaver, P. R. (1998). Self-report measurement of adult attachment: An integrative overview. In J. A. Simpson \& W. S. Rholes (Eds.), Attachment theory and close relationships (pp. 46-76). New York: Guilford.

Conroy, S. A., Becker, W. J., \& Menges, J. I. (2017). The Meaning of My Feelings Depends on Who I Am: Work-Related Identifications Shape Emotion Effects in Organizations. Academy of Management Journal, 60(3), 1071-1093.

Conroy, S., Henle, C. A., Shore, L., \& Stelman, S. (2017). Where there is light, there is dark: A review of the detrimental outcomes of high organizational identification. Journal of Organizational Behavior, 38(2), 184-203.

Dukerich, J. M., Kramer, R., \& McLean Parks, J. (1998). The dark side of organizational identification. In D. A. Whetten, \& P. C. Godfrey (Eds.), Identity in organizations: Building theory through conversations (pp. 245- 256). Thousand Oaks, CA: Sage.

Edwards, J. R., \& Cable, D. M. (2009). The value of value congruence. Journal of Applied Psychology, 94(3), 654-677. 
Elsbach, K. D. (1999). An expanded model of organizational identification. Research in Organizational Behavior, 21, 163-200.

Fraley, R. C, \&. Waller, N. G. (1998). Adult attachment patterns: A test of the typological model. In J. A. Simpson \& W. S. Rholes (Eds.), Attachment theory and close relationships (pp. 77-114). New York: Guilford Press

Glynn, M. A. (1998). Individuals need for organizational identification (nOID): speculations on individual differences in the propensity to identify. In D. A. Whetten, \& P. C. Godfrey (Eds.), Identity in organizations: Building theory through conversations (pp. 238-244). Thousand Oaks, CA: Sage.

Grady, V. M., \& Grady, J. D. (2013). The Relationship of Bowlby's Attachment Theory to the Persistent Failure of Organizational Change Initiatives. Journal of Change Management, 13(2), 206-222.

Harms, P. D. (2011). Adult attachment styles in the workplace. Human Resource Management Review, 21(4), 285-296.

Hazan, C., \& Shaver, P. R. (1990). Love and work: An attachment-theoretical perspective. Journal of Personality and Social Psychology, 59(2), 270-280.

Kreiner, G. E., \& Ashforth, B. E. (2004). Evidence toward an expanded model of organizational identification. Journal of Organizational Behavior, 25(1), 1-27.

Lee, S. M. (1971). An Empirical Analysis of Organizational Identification. Academy of Management Journal, 14(2), 213-226. 
Lee, S., \& Ling, L. (2007). Understanding affectional ties to groups from the perspective of attachment theory. In E. A. Mannix, M. A. Neale, \& C. P. Anderson (Eds.), Affect and groups (research on managing groups and teams volume 10) (pp. 217-248). Bingley, UK: Emerald.

Lee, E.-S., Park, T.-Y., \& Koo, B. (2015). Identifying organizational identification as a basis for attitudes and behaviors: A meta-analytic review. Psychological Bulletin, 141(5), 10491080.

Lopez, F. G., Mitchell, P., \& Gormley, B. (2002). Adult attachment and college student distress: Test of a mediational model. Journal of Counseling Psychology, 49, 460-467.

Lv, Z., \& Xu, T. (2018). Psychological contract breach, high-performance work system and engagement: the mediated effect of person-organization fit. The International Journal of Human Resource Management, 29(7), 1257-1284.

Mikulincer, M., Shaver, P. R., \& Rom, E. (2011). The effects of implicit and explicit security priming on creative problem solving. Cognition \& Emotion, 25(3), 519-531.

Pratt, M. G. (2000). The Good, the Bad, and the Ambivalent: Managing Identification among Amway Distributors. Administrative Science Quarterly, 45(3), 456.

Richards, D. A., \& Schat, A. C. H. (2011). Attachment at (Not to) Work: Applying Attachment Theory to Explain Individual Behavior in Organizations Conceptualizing Adult Attachment. Association, 96(1), 169-182.

Riketta, M. (2005). Organizational identification: A meta-analysis. Journal of Vocational Behavior, 66(2), 358-384. 
Rom, E., \& Mikulincer, M. (2003). Attachment theory and group processes: The association between attachment style and group-related representations, goals, memories, and functioning. Journal of Personality and Social Psychology, 84(6), 1220-1235. http://doi.org/10.1037/0022-3514.84.6.1220

Schirmer, L. L., \& Lopez, F. G. (2001). Probing the Social Support and Work Strain Relationship among Adult Workers: Contributions of Adult Attachment Orientations. Journal of Vocational Behavior, 59(1), 17-33.

Schmidt, G. B. (2016). How Adult Attachment Styles Relate to Perceived Psychological Contract Breach and Affective Organizational Commitment. Employee Responsibilities and Rights Journal, 28(3), 147-170.

Shaver, P., \& Hazan, C. (1987). Being Lonely, Falling in Love. Journal of Social Behavior and Personality, 2(2), 105.

Simpson, J. A., \& Rholes, W. S. (2002). Fearful-avoidance, disorganization, and multiple working models: Some directions for future theory and research. Attachment \& Human Development, 4(2), 223-229.

Smith, E. R., Murphy, J., \& Coats, S. (1999). Attachment to groups: Theory and management. Journal of Personality and Social Psychology, 77(1), 94-110.

Thompson, M. M., \& Holmes, J. G. (1996). Ambivalence in close relationships: conflicted cognitions as a catalyst for change. In R. M. Sorrentino, \& E. T. Higgins (Eds.), Handbook of Motivation and Cognition. Vol. 3: The interpersonal context (pp. 497-530). New York: Guilford Press. 
Überschaer, A., Baum, M., Bietz, B.-T., \& Kabst, R. (2016). The contingencies of personorganization fit perceptions. Journal of Managerial Psychology, 31(6), 109-117.

Van Dick, R., Christ, O., Stellmacher, J., Wagner, U., Ahlswede, O., Grubba, C., ... Tissington, P. A. (2004). Should I Stay or Should I Go? Explaining Turnover Intentions with Organizational Identification and Job Satisfaction. British Journal of Management, $15(4), 351-360$.

Wei, M., Heppner, P. P., Russell, D. W., \& Young, S. K. (2006). Maladaptive perfectionism and ineffective coping as mediators between attachment and subsequent depression: A prospective analysis. Journal of Counseling Psychology, 53, 67-79.

Wu, C.-H., \& Parker, S. K. (2017). The Role of Leader Support in Facilitating Proactive Work Behavior. Journal of Management, 43(4), 1025-1049.

Wu, C.-H., Parker, S. K., \& de Jong, J. P. (2014). Feedback seeking from peers: A positive strategy for insecurely attached team-workers. Human Relations, 67(4), 441-464.

Yip, J., Ehrhardt, K., Black, H., \& Walker, D. O. (2018). Attachment theory at work: A review and directions for future research. Journal of Organizational Behavior, 39(2), 185-198.

Zakalik, R. A., \& Wei, M. (2006). Adult attachment, perceived discrimination based on sexual orientation, and depression in gay males. Journal of Counseling Psychology, 53, 302313. 
Table 1 -Means, Standard Deviations and Correlations

\begin{tabular}{|c|c|c|c|c|c|c|c|c|c|c|}
\hline Variable & 1 & 2 & 3 & 4 & 5 & 6 & 7 & 8 & 9 & 10 \\
\hline 1. Attachment Anxiety & $(.94)$ & & & & & & & & & \\
\hline 2. Attachment Avoidance & $.27 * *$ & $(.94)$ & & & & & & & & \\
\hline $\begin{array}{l}\text { 3. Organizational } \\
\text { Identification }\end{array}$ & .08 & $-.15 * *$ & $(.85)$ & & & & & & & \\
\hline 4. Disidentification & $.29 * *$ & $.26 * *$ & $-.28 * *$ & $(.89)$ & & & & & & \\
\hline $\begin{array}{l}\text { 5. Ambivalent } \\
\text { Identification }\end{array}$ & $.31 * *$ & $.23 * *$ & $-.14 * *$ & $.74 * *$ & $(.91)$ & & & & & \\
\hline 6. Neutral Identification & $.12^{*}$ & $.20 * *$ & $-.61 * *$ & $.45^{* *}$ & $.37 * *$ & $(.91)$ & & & & \\
\hline 7. NOID & .08 & $-.23 * *$ & $.54 * *$ & $-.18 * *$ & $-.18 * *$ & $-.44 * *$ & $(.82)$ & & & \\
\hline 8. P-O Fit & -.02 & $-.18 * *$ & $.52 * *$ & $-.38 * *$ & $-.32 * *$ & $-.43 * *$ & $-.44 * *$ & $(.93)$ & & \\
\hline 9. Sex & -.05 & -.03 & -.08 & .07 & .02 & $.12 *$ & -.01 & .07 & - & \\
\hline 10. Age & $-.22 * *$ & -.04 & -.05 & .04 & -.01 & $-.11 *$ & .03 & -.09 & -.03 & - \\
\hline Mean & 3.41 & 3.31 & 3.22 & 1.80 & 2.30 & 2.38 & 3.41 & 3.67 & .61 & 34.72 \\
\hline SD & 1.23 & 1.16 & 0.95 & 0.86 & 1.02 & 1.03 & 0.80 & 0.95 & NA & 8.90 \\
\hline
\end{tabular}

Note: $* p<.05 ; * *<.01$. Coefficient alpha reliability estimates are in parenthesis on the main diagonal. 
Table 2 - Pattern of Correlation Coefficients

$\begin{array}{llll}\text { Variable } & \text { Anxiety } & \text { Avoidance } & \mathrm{R}^{2}\end{array}$

$\begin{array}{llll}\text { 1. Organizational } & .10 * & -.15^{* *} & .04\end{array}$

Identification

$\begin{array}{llll}\text { 2. Disidentification } & .16^{* *} & .14^{* *}\end{array}$

3. Ambivalent $\quad .22 * * \quad .14 * \quad .12$

Identification

$\begin{array}{llll}\text { 4. Neutral } & .06 & .16^{* *} & .05\end{array}$

Identification

Note: ${ }^{*} p<.05 ; * * p<.01$. 
Table 3 - Hierarchical Multiple Regression Testing Moderation Effect of nOID

\begin{tabular}{|c|c|}
\hline Variables & ID \\
\hline \multicolumn{2}{|l|}{ Step 1} \\
\hline Anxiety & $.10^{*}$ \\
\hline Avoidance & $-.15^{* *}$ \\
\hline $\mathrm{R}^{2}$ & .03 \\
\hline \multicolumn{2}{|l|}{ Step 2} \\
\hline Anxiety & .04 \\
\hline Avoidance & -.03 \\
\hline nOID & $.63 * *$ \\
\hline$\Delta \mathrm{R}^{2}$ & .26 \\
\hline \multicolumn{2}{|l|}{ Step 3} \\
\hline Anxiety & .05 \\
\hline Avoidance & -.04 \\
\hline nOID & $.62 * *$ \\
\hline Anxiety $\mathrm{X}$ nOID & .00 \\
\hline Avoidance $\mathrm{X}$ nOID & -.08 \\
\hline$\Delta \mathrm{R}^{2}$ & .01 \\
\hline Total $\mathrm{R}^{2}$ & .30 \\
\hline
\end{tabular}

Note: ${ }^{*} p<.05 ; * * p<.01$. 
Table 4 - Hierarchical Multiple Regression Testing Moderation Effect of PO Fit

\begin{tabular}{|c|c|c|c|}
\hline Variables & ID & DISID & Ambivale \\
\hline \multicolumn{4}{|l|}{ Step 1} \\
\hline Anxiety & $.10^{*}$ & $.16^{* *}$ & $.22 * *$ \\
\hline Avoidance & $-.15 * *$ & $.14^{* *}$ & $.14^{* *}$ \\
\hline $\mathrm{R}^{2}$ & .04 & .12 & .12 \\
\hline \multicolumn{4}{|l|}{ Step 2} \\
\hline Anxiety & $.09^{*}$ & $.17 * *$ & $.23 * *$ \\
\hline Avoidance & -.07 & $.09^{*}$ & $.09^{*}$ \\
\hline PO Fit & $.50 * *$ & $-.32 * *$ & $-.32 * *$ \\
\hline$\Delta \mathrm{R}^{2}$ & .24 & .12 & .09 \\
\hline
\end{tabular}

Step 3

\begin{tabular}{cccc} 
Anxiety & $.10 * *$ & $.17 * *$ & $.23 * *$ \\
Avoidance & -.07 & $.09 *$ & $.10^{*}$ \\
PO Fit & $.50 * *$ & $-.32 * *$ & $-.32 * *$ \\
Anxiety X PO Fit & -.01 & $.08 *$ & -.03 \\
Avoidance X PO Fit & -.07 & -.06 & -.04 \\
$\Delta \mathrm{R}^{2}$ & .01 & .01 & .00 \\
Total $\mathrm{R}^{2}$ & .28 & .25 & .21 \\
\hline
\end{tabular}

Note: ${ }^{*} p<.05 ; * * p<.01$. 
Table 5. - Predicted Relationships

\begin{tabular}{|l|c|c|c|c|}
\hline & $\begin{array}{c}\text { Organizational } \\
\text { Identification }\end{array}$ & Disidentification & $\begin{array}{c}\text { Ambivalent } \\
\text { Identification }\end{array}$ & $\begin{array}{c}\text { Neutral } \\
\text { Identification }\end{array}$ \\
\hline $\begin{array}{l}\text { Attachment } \\
\text { Anxiety }\end{array}$ & + & + & + & - \\
\hline Avoidance & - & + & + & + \\
\hline
\end{tabular}


Figure 1. - Graph of moderation effect of PO Fit on the relationship between attachment anxiety and disidentification

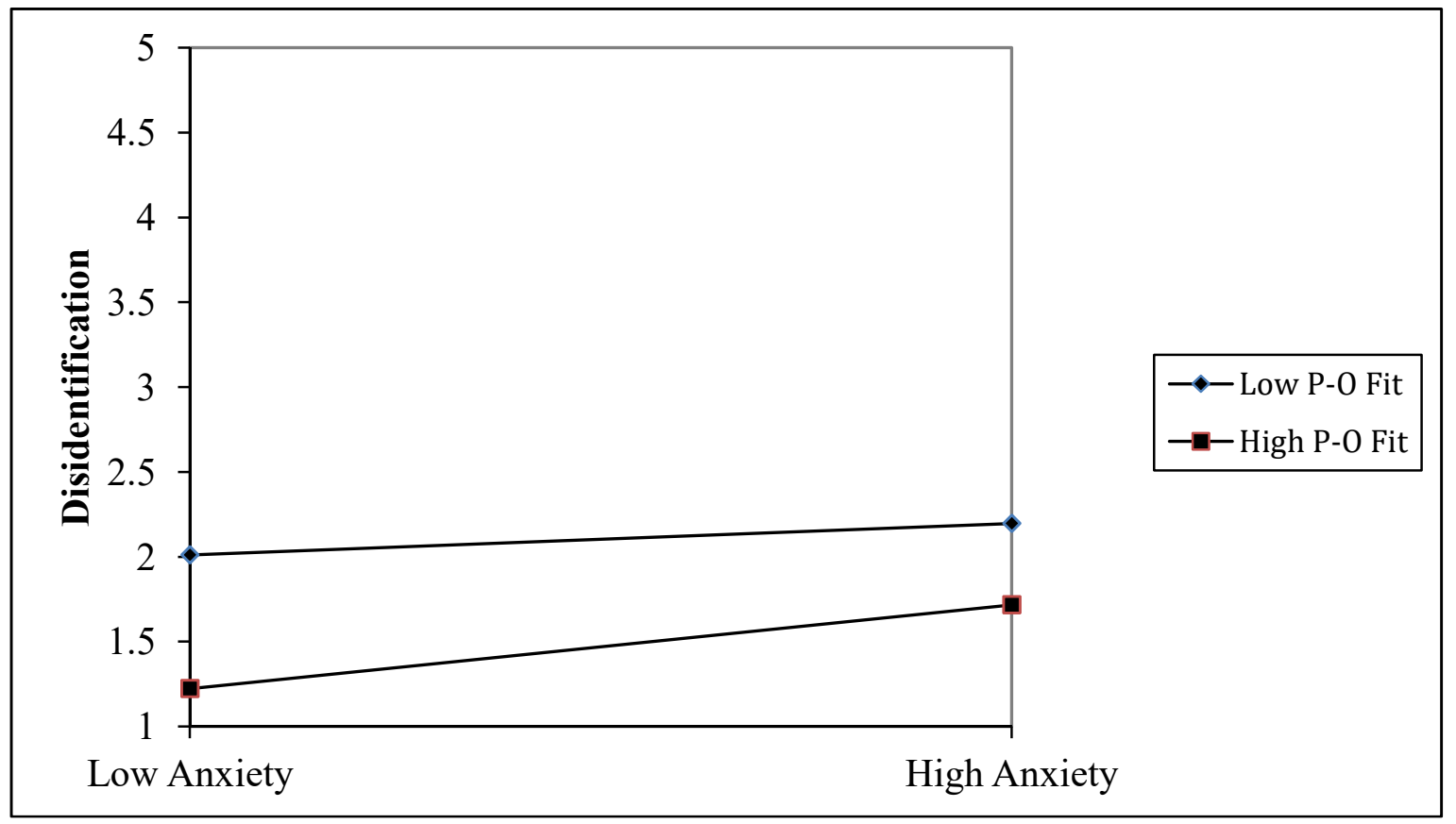

